\title{
Editorial
}

\section{Acknowledgement to Reviewers of the Journal of Developmental Biology in 2014}

$J D B$ Editorial Office, MDPI AG, Klybeckstrasse 64, CH-4057 Basel, Switzerland

Published: 9 January 2015

The editors of the Journal of Developmental Biology would like to express their sincere gratitude to the following reviewers for assessing manuscripts in 2014:

$\begin{array}{lll}\text { Bogart, James } & \text { Immink, Richard } & \text { Rochais, Francesca } \\ \text { Brown, Geoffrey } & \text { Lamb, Dolores } & \text { Ruehl, Ralph } \\ \text { Bueno, David } & \text { Lehtinen, Maria } & \text { Schubert, Michael } \\ \text { Bush, Jeffrey } & \text { Loveland, Kate } & \text { Si-Tayeb, Karim } \\ \text { Camenisch, Todd D. } & \text { Mendez Ferrer, Simon } & \text { Smart, Nicola } \\ \text { Chen, Yiping } & \text { Mikawa, Takashi } & \text { Sockanathan, Shanthini } \\ \text { Chernoff, Ellen A. G. } & \text { Miyan, Jaleel } & \text { Sofroniew, Michael V. } \\ \text { Desmond, ME } & \text { Montero, Juan Antonio } & \text { Sucov, Henry } \\ \text { Everts, Helen } & \text { Mukhtar, Shahid M. } & \text { Tallquist, Michelle } \\ \text { Ferretti, Patrizia } & \text { Muñoz-Chápuli, Ramón } & \text { Torella, Daniele } \\ \text { Gaspar, Maria Luisa } & \text { Nadal-Ginard, Bernardo } & \text { Wakabayashi, Ichiro } \\ \text { Gittenberger-De Groot, A. C. } & \text { Niederreither, Karen } & \text { Wilhelm, Dagmar } \\ \text { Goldberg, Erwin } & \text { Panakova, Daniela } & \text { Xie, Yan } \\ \text { Goriely, Anne } & \text { Perez-Pomares, Jose-Maria } & \text { Yutzey, Katherine } \\ \text { Heideman, Warren } & \text { Petroll, Matthew } & \text { Zile, M } \\ \text { Horsley, Valerie } & \text { Pucéat, Michel } & \\ \text { Hurlé, Juan } & \text { Rezsohazy, Rene } & \end{array}$

(C) 2015 by the authors; licensee MDPI, Basel, Switzerland. This article is an open access article distributed under the terms and conditions of the Creative Commons Attribution license (http://creativecommons.org/licenses/by/4.0/). 